\title{
Renal scarring after acute pyelonephritis
}

\author{
Birgir Jakobsson, Ulla Berg, Leif Svensson
}

\begin{abstract}
Seventy six children, 18 boys and 58 girls, aged $0-15.9$ (median 1.0 ) years, with acute pyelonephritis were prospectively studied with a technetium-99m dimercaptosuccinic acid (DMSA) scan during infection and two months later. Fifty nine of these children were also studied two years after the infection. Seventeen children with a normal DMSA scan during infection or at two months after infection, or both, were not investigated by a DMSA scan at two years after acute pyelonephritis. A micturition cystourethrogram was performed in all the children after two months. Changes on the DMSA scan were found in $65(86 \%)$ children during acute pyelonephritis, in $45(59 \%)$ children at two months, and in $28(37 \%)$ children at two years after infection. Vesicoureteric reflux (VUR) was found in $19(25 \%)$ children at two months. Renal scarring was significantly correlated with the presence of gross VUR and recurrent pyelonephritis, but $62 \%$ of the scarred kidneys were drained by non-refluxing ureters. Children with scars were older at the time of acute pyelonephritis than those without scars but no difference was found between the groups with regard to duration of illness, levels of $\mathrm{C}$ reactive protein and maximum white cell count, glomerular filtration rate, nor renal concentration capacity at the time of infection. It is concluded that renal scarring after acute pyelonephritis in children is more common than has been previously thought. Although children with gross VUR and recurrent pyelonephritis are at the greatest risk, renal scarring is more often seen without these risk factors.

(Arch Dis Child 1994; 70: 111-115)
\end{abstract}

Acute pyelonephritis in children may result in permanent renal damage, which later in life may lead to hypertension and renal failure. ${ }^{1}$ The diagnosis of acute pyelonephritis is based on indirect tests and clinical parameters, which are not 'entirely reliable in infants. Moreover, our present understanding of renal scarring is mainly based on information derived from intravenous urography. It has been shown previously in experimental ${ }^{2-4}$ and clinical studies $^{56}$ that the technetium-99m dimercaptosuccinic acid (DMSA) scan is probably the most sensitive method available for diagnosing and localising acute pyelonephritis. Moreover, the DMSA scan is more sensitive than intravenous urography for detecting renal scarring. ${ }^{7}{ }^{8}$ The DMSA scan therefore offers a unique opportunity to study the progression of the acute insult after pyelonephritis and the subsequent development of renal scarring.

Previous studies have shown that renal scarring was almost always associated with vesicoureteric reflux (VUR). ${ }^{9}$ Later studies using the DMSA scan, however, have suggested that scarring may often occur in the absence of VUR, ${ }^{5}$ and it has been claimed that renal scarring may be independent of the presence or absence of VUR. ${ }^{10}$ We therefore need to reassess our knowledge in this field on the basis of studies in which acute pyelonephritis has been diagnosed and followed up with DMSA scans.

The aim of this prospective clinical study was to determine the incidence of renal scarring after acute pyelonephritis and how this correlated with previously well known risk factors such as VUR, age, delay in starting treatment, and recurrent urinary tract infections.

\section{Patients and methods}

Seventy six patients ( 152 kidneys), 18 boys and 58 girls, aged $0-15.9$ (median $1 \cdot 0$ ) years, consecutively admitted to our hospital with the clinical diagnosis of acute pyelonephritis were studied with a DMSA scan within five days of admission and about two months later. Figure 1 gives the age and sex distributions of the children. Acute pyelonephritis was defined as fever $\geqslant 38.5^{\circ} \mathrm{C}, \mathrm{C}$ reactive protein $>20 \mathrm{mg} / \mathrm{l}$, or erythrocyte sedimentation rate $>20 \mathrm{~mm} /$ hour, and a positive urinary culture. The laboratory data during acute pyelonephritis in most of these children have been published previously. ${ }^{5}$ All the children were available for long term follow up and a DMSA scan was performed in 59 $(78 \%)$ of them after two years. The remaining $17(22 \%)$ children had a normal DMSA scan at two months and $11(65 \%)$ of these also had a normal DMSA scan during infection. After the initial treatment, all children received prophylactic antibiotics until the second investigation at two months, and none had a breakthrough infection during that time.

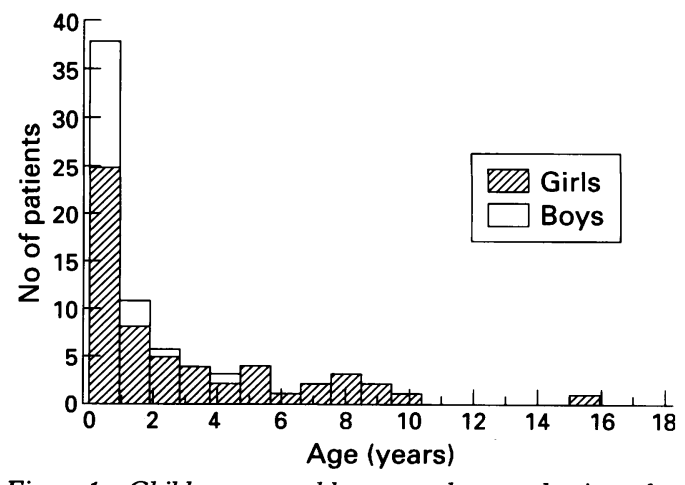

Figure 1 Children grouped by age and sex at the time of acute pyelonephritis. 
The DMSA scan was performed with the children supine and immobilised in a vacuum pillow. Technetium-99m dimercaptosuccinic acid was given at a dose of $0.5 \mathrm{MBq} / \mathrm{kg}$ body weight (minimum $10 \mathrm{MBq}$ ). At least three hours after the injection, a 500000 count posterior picture was taken. All DMSA scans were evaluated visually and with a computerised method in which each DMSA scan was compared with a database of DMSA scans collected from children who were defined retrospectively as having normal DMSA scans and no signs of acute pyelonephritis. Regional kidney zones, with a cortical uptake below two standard deviations of the uptake in the normal group, were delineated. These zones were colour coded in a functional image and their contributions to the total kidney were given as a measure of the extension of the decrease in cortical uptake. The DMSA scan was considered abnormal if one or more areas of decreased cortical uptake were noted with or without preservation of the cortical outline.

All children had a micturition cystourethrogram performed at two months after the initial infection. The presence of VUR was noted and graded on a scale from 0 to 5 in accordance with the International Reflux Study. ${ }^{11}$ Children with VUR grade $\geqslant 3$ received antibiotic prophylaxis for a period of at least one year, until spontaneous regression of reflux, or until they had an operation.

The laboratory tests in these patients at the time of the acute infection included a white cell count, measurement of $\mathrm{C}$ reactive protein, serum creatinine, urine osmolality after the desmopressin test, ${ }^{5}$ and a urine culture. The maximum urinary concentrating capacity was expressed as a SD score, which was calculated by the method of Mårild et al. ${ }^{12}$ The glomerular filtration rate was calculated using the formula clearance. ${ }^{513}$

Mann-Whitney's non-parametric test and the $\chi^{2}$ test were used for statistical analyses; $p$ $<0.05$ was considered significant.

This study was approved by the local ethics committee.

\section{Results}

During infection, changes were found on the DMSA scan in $65(86 \%)$ children and 100 $(66 \%)$ kidneys. At two months after initial infection, $45(59 \%)$ children had persistent changes on DMSA scan in $58(38 \%)$ kidneys. At two years an abnormal scan was found in 28 $(47 \%)$ of the 59 children investigated with a DMSA scan in $37(24 \%)$ kidneys. Changes at two years were found only at sites that had

Table 1 Relation between VUR at two months and renal scarring at two years after acute pyelonephritis. Values are number (\%) of kidneys with each grade of VUR

\begin{tabular}{lll} 
& \multicolumn{2}{l}{ DMSA scan } \\
\cline { 2 - 3 } Grade of VUR & Scarring & No scarring \\
\hline 0 & $23(19)$ & $96(81)$ \\
$1-2$ & $5(29)$ & $12(71)$ \\
$\geqslant 3$ & $9(56)^{\star}$ & $7(44)$ \\
\hline
\end{tabular}

${ }^{\star} \mathrm{p}<0.01$ compared with grade 0 VUR.

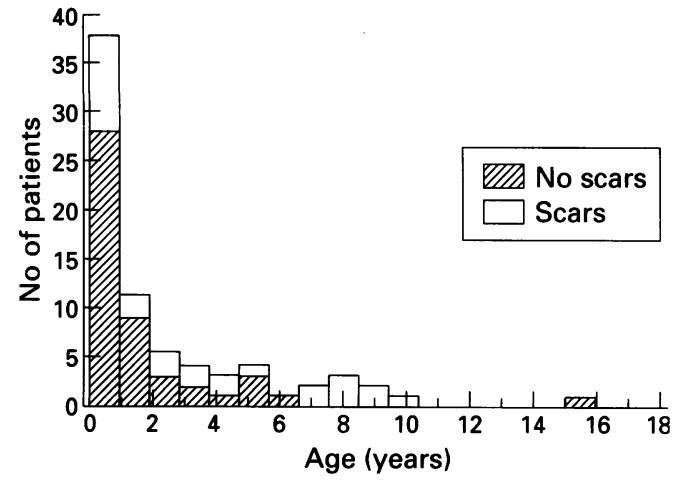

Figure 2 Age distributions at the time of infection in children with and without scars.

shown pyelonephritis changes during infection. No kidney that was normal during infection or at two months after infection showed any abnormality at two years. Assuming therefore that the 17 children with previously normal kidneys, and not investigated with a DMSA scan at two years after infection, would remain normal, $37 \%$ of all children showed signs of permanent renal damage.

VUR was found in $19(25 \%)$ children (33 ureters) at two months after infection, grades $1-2$ in nine (12\%) (17 ureters) and grade $\geqslant 3$ in $10(13 \%)$ children (16 ureters). Table 1 gives the relation between renal scarring on DMSA scan at two years after infection and the grade of reflux at two months. Renal scarring was significantly more common in kidneys with reflux grade $\geqslant 3$ than in kidneys without reflux, but $23 / 37(62 \%)$ of the scarred kidneys were drained by non-refluxing ureters.

Scars were seen more often in girls $(24 / 58$, $41 \%)$ than in boys $(4 / 18,22 \%)$, but the difference was not significant (table 2). Figure 2 gives the age distributions at the time of infection in children with and without scars. Children with scars were significantly older at the time of infection than those who did not develop scars $(p<0.02)$ (table 2). No significant difference was found between children with or without scars with respect to duration of illness, expressed as number of days with fever, $\mathrm{C}$ reactive protein, maximum white cell count, glomerular filtration rate, or renal concentrating capacity during the infection (table 3). Escherichia coli was the infecting agent in $72(95 \%)$ patients and other bacteria were found in four patients, all of whom had scars (table 3 ).

Recurrent urinary tract infection occurred in $13(17 \%)$ children during the follow up period. These included recurrent pyelonephritis in

Table 2 Age at the time of infection and sex in relation to scars two years after acute pyelonephritis $(n=76)$

\begin{tabular}{lcc}
\hline & \multicolumn{2}{c}{ DMSA scan } \\
\cline { 2 - 3 } & Scarring & No scarring \\
\hline Sex & & \\
$\quad$ Boys & 4 & 14 \\
$\quad$ Girls & 24 & 34 \\
Age (years) & & \\
$\quad$ Mean (SD) & $3.6(3.4)$ & $1 \cdot 7(2 \cdot 6)^{\star}$ \\
Range & $0 \cdot 1-9.8$ & $0-15 \cdot 9$ \\
\hline${ }^{\star} \mathrm{p}<0.02$. & & \\
\end{tabular}


Table 3 Relation between renal scarring at two years after infection in 76 patients and clinical data at the time of acute pyelonephritis

\begin{tabular}{|c|c|c|c|}
\hline & \multicolumn{3}{|l|}{ DMSA scan } \\
\hline & $\begin{array}{l}\text { Scarring } \\
(n=28)\end{array}$ & $\begin{array}{l}\text { No scarring } \\
(n=48)\end{array}$ & p Value \\
\hline $\begin{array}{l}\text { Duration of fever (days) })^{\star} \\
\text { C reactive protein }(\mathrm{mg} / 1)^{\star} \\
\text { White cell count }\left(\times 10^{9} /\right)^{\star} \\
\text { Glomerular filtration rate }\left(\mathrm{ml} / \mathrm{min} / 1 \cdot 73 \mathrm{~m}^{2}\right)^{\star} \\
\text { Concentrating capacity }(\mathrm{SD} \text { score })^{\star}\end{array}$ & $\begin{array}{l}3 \cdot 2(2 \cdot 1) \\
133(79) \\
17 \cdot 3(7 \cdot 6) \\
77(21) \\
-2 \cdot 5(1 \cdot 4)\end{array}$ & $\begin{array}{l}3 \cdot 1(2 \cdot 6) \\
101(65) \\
18 \cdot 9(7 \cdot 1) \\
80(26) \\
-2 \cdot 5(1 \cdot 4)\end{array}$ & $\begin{array}{l}\text { NS } \\
\text { NS } \\
\text { NS } \\
\text { NS } \\
\text { NS }\end{array}$ \\
\hline $\begin{array}{l}\text { Urine culture } \\
\quad E \text { coli } \\
\text { Other bacteria }\end{array}$ & $\begin{array}{r}24 \\
4\end{array}$ & $\begin{array}{r}48 \\
0\end{array}$ & $<0.05$ \\
\hline
\end{tabular}

*Values are means (SD).

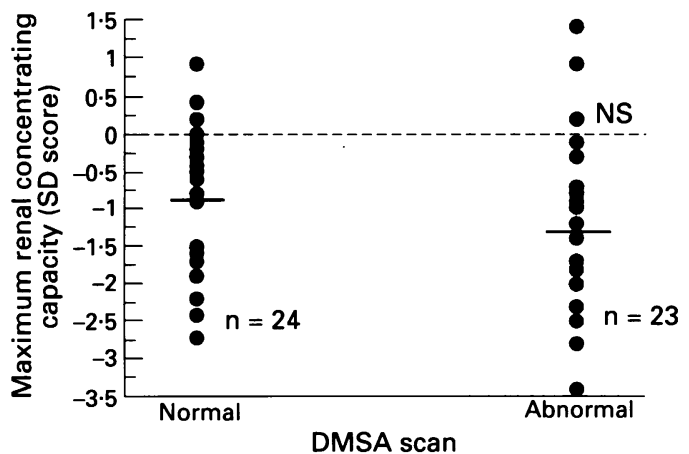

Figure 3 Standard deviation score for renal concentrating capacity using the method of Marild et $\mathrm{al}^{12}$ in children two years after acute pyelonephritis with or without renal scarring on DMSA scan. infections in five $(7 \%)$ (one child had both types). Of the children with recurrent pyelonephritis, five had VUR grade $\geqslant 3$, whereas four had no reflux. All children with recurrent pyelonephritis developed scars. Table 4 gives the relation between renal scarring and VUR in the nine children with recurrent pyelonephritis. As can be seen by comparing table 4 with table 1 , six of the nine scarred kidneys with reflux grade $\geqslant 3$ were in children who had recurrent pyelonephritis. All these kidneys, however, had a decreased uptake on DMSA scan at two months after the acute pyelonephritis. None of the five children with recurrences of lower urinary tract infection had VUR. Two of these children developed scars, one girl who also had a recurrence of pyelonephritis and a 9 year old girl who had four recurrences of lower urinary tract infection after her acute pyelonephritis.

At the two year follow up there was no significant difference in renal concentrating capacity, expressed as SD score, between the group with scars and the group without scars (fig 3), nor was there any difference in glomerular filtration rate between the two groups: 88 (13) (24 children) and 88 (14) (27 children) $\mathrm{ml} / \mathrm{min} / 1.73 \mathrm{~m}^{2}$ respectively.

\section{Discussion}

Permanent renal damage in children after acute pyelonephritis has been estimated to occur in $5-20 \%$ of cases. ${ }^{1415}$ These numbers are based on findings seen on intravenous urography, which is a less sensitive method for detecting renal scars than a DMSA scan. ${ }^{78}$ Hardly any prospective studies using a DMSA scan to diagnose acute pyelonephritis and for long term follow up have been carried out. Rushton et al have published a study of 66 children with acute pyelonephritis, but almost half of these children were lost to follow up. ${ }^{10}$ We have followed up all of our 76 children for

Table 4 Renal scarring in relation to grade of VUR in nine children (18 kidneys) with recurrent pyelonephritis. Values are number of kidneys

\begin{tabular}{lll}
\hline \multirow{2}{*}{ Grade of VUR } & \multicolumn{2}{l}{ DMSA scan } \\
\cline { 2 - 3 } \cline { 2 - 2 } & Scarring & No scarring \\
\hline 0 & 5 & 4 \\
$1-2$ & 1 & 0 \\
3 & 6 & 2
\end{tabular}

at least two years and performed a DMSA scan in 59 of them two years after the infection. Those who did not have a DMSA scan after two years had a normal scan during the infection or at two months after the infection, or both, which allows the assumption that their kidneys remained normal. We have previously argued that our patients represent an unselected group of children with acute pyelonephritis. ${ }^{5}$ Our study therefore shows that, with the use of the DMSA scan, the incidence of renal scarring after acute pyelonephritis in children of $37 \%$ is considerably higher than has previously been thought. During infection $100(66 \%)$ kidneys showed signs of acute pyelonephritis. After two years only 36 (24\%) kidneys showed signs of scarring. Thus the acute inflammatory changes had completely resolved in $64 \%$ of the kidneys. This is nearly identical with the results of Rushton et al. ${ }^{10}$

VUR has been considered almost a prerequisite for the development of renal scars. ${ }^{9}$ With the increased use of DMSA scans in the follow up of children with acute pyelonephritis, we have become increasingly aware of the fact that scars, in many patients, develop without the presence of reflux. It has been suggested that the role of VUR as a risk factor may only be related to its role as a risk factor for acute pyelonephritis. ${ }^{10}$ Although $62 \%$ of the scarred kidneys in this study had no reflux, our results show that the risk of a kidney becoming scarred increases in the presence of gross reflux (grade $\geqslant 3$ ) as $56 \%$ of these kidneys became scarred, compared with $19 \%$ of the kidneys without reflux. In spite of prophylactic treatment, five patients with gross reflux had recurrent pyelonephritis. This was due to either breakthrough infections (three children) or non-compliance (two children). As can be seen by comparing table 1 with table 4 , six of the nine scarred kidneys with gross reflux occurred in patients with recurrent pyelonephritis. As all these kidneys had reduced DMSA uptake at two months after the pyelonephritis and before any recurrences occurred, however, it is probable that the gross reflux itself, in combination with infection, is a risk factor for the kidney. The scarring may have become more severe because of the recurrent infections and, as can be seen in table 4 , recurrent pyelonephritis is dangerous to the kidneys, as five of nine non-refluxing kidneys 
became scarred. This study confirms the observations made by us and others ${ }^{516-18}$ that renal scarring is more common in the absence of VUR than has previously been thought.

We were surprised to find that children with scars were older at the time of acute pyelonephritis than those without scars. A thorough consideration of the earlier history of our children showed that two older girls had a history of suspected urinary tract infection and two other girls had a history of recurrent febrile episodes during the first year of life. Even if these girls are excluded, the children with scars were older at the time of infection than those without scars. The difference, however, was not significant. Earlier studies based on intravenous urography have shown that infants and children younger than 3 years with acute pyelonephritis are at the greatest risk of developing renal scarring or a compromised renal function. ${ }^{14} 18$ Smellie et al showed that new scars were often seen up to the age of 7 years, but even occurred until the age of 10 years. ${ }^{15}$ The findings in the present study are also supported by those of Rushton et al, who found that the group with scars was older than the group without, ${ }^{10}$ though the difference was not significant. It is possible that some older children with acute pyelonephritis may have had pyelonephritis during infancy which was not detected, but our results support the observations made by Smellie et $a l^{15}$ that all preschool children are at risk of developing permanent renal damage after acute pyelonephritis.

We found no difference between the groups with or without scars with respect to the duration of fever and the levels of $\mathrm{C}$ reactive protein or white cell count at the time of infection. Therapeutic delay has been associated with an increased frequency of renal scarring in experimental ${ }^{19}$ and clinical reports. ${ }^{1520}$ In this study, most of the children were referred within the first three or four days of fever and none after more than seven days. Our results therefore suggest that there is no difference in the frequency of renal scarring if treatment is started within the first week of infection. Toxic metabolites released from infiltrating polymorphonuclear leucocytes have been shown to damage the renal tissue ${ }^{21}$ and drugs inhibiting leucocytes protect against acquired renal scarring in animals. ${ }^{22}$ We found high levels of peripheral leucocytes in the two groups, however, suggesting that some local factors in the kidney may be important.

The renal concentrating capacity has been considered of value for detecting renal disease after acute pyelonephritis, ${ }^{2324}$ and we have previously found a correlation between the size of the defect on DMSA scan and the renal concentrating capacity during infection. ${ }^{5}$ Moreover, children with persistent changes on DMSA scan two months after infection continue to have a significantly lower concentrating capacity than those with a normal DMSA scan. ${ }^{25}$ As shown in this study, the renal concentrating capacity during pyelonephritis is a poor predictor of renal scarring and is not a sensitive indicator of renal scarring after two years, as shown in fig 3 .
The glomerular filtration rate during infection, calculated as formula clearance, was not a predictor of renal scarring and there was no difference in the glomerular filtration rate at two years between the group with scars and the group without scars. It has been shown that children who have had one episode of pyelonephritis show a lower glomerular filtration rate than healthy controls, which is in agreement with this study, and the glomerular filtration rate was lower in children with renal scars and recurrent pyelonephritis episodes. ${ }^{26} 27$ In these studies renal scars were detected by intravenous urography and therefore they may have been larger than the scars detected in this study by a DMSA scan.

$E$ coli was found in the urine in $95 \%$ of our patients. The bacteria were not studied with regard to P-fimbriae, but no correlation between P-fimbriae and renal scarring was found in a previous study. ${ }^{28}$ In agreement with the former study, other bacteria were seen only in children who developed scars; two of these children had reflux. Moreover, two of the children with recurrent breakthrough infections had Pseudomonas aeruginosa in their urine. This supports previous observations that, in many patients, less virulent bacteria may be harmful to hosts with decreased resistance. ${ }^{29}$

In conclusion, this study shows that renal scarring after acute pyelonephritis in children is considerably more common than was previously thought and may be expected to occur in about one third of all children with acute pyelonephritis. All preschool children seem to run the same risk of renal scarring. Renal scarring often occurs in the absence of VUR, but children with gross reflux and recurrent pyelonephritis are at greatest risk.

This study was supported by grants from the Karolinska Institute, the Samariten Foundation and the Swedish Medical Research Council (No 6864).

1 Jacobson SH, Eklöf O, Lins LE, Wikstad I, Winberg J. Long-term prognosis of post-infectious renal scarring in relation to radiological findings in childhood - a 27-year follow-up. Pediatr Nephrol 1992; 6: 19-24.

2 Rushton HG, Majd M, Chandra R, Yim D. Evaluation of ${ }_{99 \mathrm{~m}}$ Technetium-dimercapto-succinic acid renal scans in experimental acute pyelonephritis in piglets. $\mathcal{F}$ Urol 1988; 140: $1169-74$.

3 Parkhouse HF, Godley ML, Cooper J, Risdon RA, Ransley PG. Renal imaging with ${ }^{99} \mathrm{Tc}^{\mathrm{m}}$-labelled DMSA in the detection of acute pyelonephritis: an experimental study in the pig. Nucl Med Commun 1989; 10: 63-70.

4 Wikstad I, Hannerz L, Karlsson A, Eklöf AC, Olling S Aperia A. ${ }^{99}$ Technetium dimercaptosuccinic acid scintigraphy in the diagnosis of acute pyelonephritis in rats. Pediatr Nephrol 1990; 4: 331-4.

5 Jakobsson B, Nolstedt L, Svensson L, Söderlundh S, Berg U. $99 \mathrm{~m}$ Tc-Dimercaptosuccinic acid (DMSA) scan in the diagnosis of acute pyelonephritis in children: relation to diagnosis of acute pyelonephritis in children: relation to 328-34.

6 Majd M, Rushton HG. Renal cortical scintigraphy in the diagnosis of acute pyelonephritis. Semin Nucl Med 1992; 22: 98-111.

7 Goldraich NP, Ramos OL, Goldraich IH. Urography versus DMSA scan in children with vesicoureteric reflux. Pediat Dephrol 1989; 3: 1-5.

8 Whitear P, Shaw P, Gordon I. Comparison of ${ }^{99} \mathrm{Tcm}$ dimercaptosuccinic acid scans and intravenous urography in children. Br f Radiol 1990; 63: 438-43.

9 Smellie J, Edwards D, Hunter N, Normand ICS, Prescod N. Vesicoureteric reflux and renal scarring. Kidney Int 1975; 8: 65-72.

10 Rushton HG, Majd M, Jantausch B, Wiedermann BL Belman AB. Renal scarring following reflux and nonreflux pyelonephritis in children: evaluation with $99 \mathrm{~m}$ technetium dimercaptosuccinic acid scintigraphy. $\mathcal{F}$ Urol 1992; 147 1327-32. 
11 Report of the International Reflux Study Committee. Medical versus surgical treatment of primary vesicoureteric reflux: a prospective international reflux study in children. 7 Urol 1981; 125: 277-83.

12 Mårild $\mathrm{S}$, Jodal U, Jonasson $\mathrm{G}$, Mangelus $\mathrm{L}$, Odén $\mathrm{A}$, Persson N-G. Reference values for renal concentrating capacity in child

13 Schwartz GJ, Brion LP, Spitzer A. The use of plasma creatinine for estimating glomerular filtration rate in infants, children, and adolescents. Pediatr Clin North Am infants, children, a

14 Pylkkänen J, Vilska J, Koskimies $O$. The value of level diagnosis of childhood urinary tract infection in predicting renal injury. Acta Paediatr Scand 1981; 70: 879-83.

15 Smellie JM, Ransley PG, Normand ICS, Prescod N, Edwards D. Development of new renal scars: a collaborative study. BMF 1985; 290: 1957-60.

16 Rushton HG, Majd M. Dimercaptosuccinic acid renal scintigraphy for the evaluation of pyelonephritis and scarring: a review of experimental and clinical studies. $f$ Urol 1992; 148: 1726-32.

17 Verber IG, Strudley MR, Meller ST. ${ }^{99} \mathrm{~m}$ Tc dimercaptosuccinic acid (DMSA) scan as first investigation of urinary cinic acid (DMSA) scan as first investigation of
tract infection. Arch Dis Child 1988; 63: 1320-5.

18 Berg UB, Johansson SB. Age as a main determinant of renal functional damage in urinary tract infection. Arch Dis Child 1983; 58: 963-9.

19 Miller T, Phillips S. Pyelonephritis: the relationship between infection, renal scarring, and antimicrobial therapy. Kidney Int 1981; 19: 654-62.

20 Winberg J, Bollgren I, Källenius G, Möllby R, Svenson SB Clinical pyelonephritis and focal renal scarring. A selected review of pathogenesis, prevention, and prognosis. Pediatr Clin North Am 1982; 29: 801-14.

21 Glauser MP, Meylan P, Bille J. The inflammatory response and tissue damage. The example of renal scars following acute renal infection. Pediatr Nephrol 1987; 1: 615-22.

22 Bille J, Glauser MP. Protection against chronic pyelonephritis in rats by suppression of acute suppuration: effect of colchicine and neutropenia. $\mathcal{F}$ Infect Dis 1982; 146: $220-6$.

23 Jodal U, Lindberg U, Lincoln $\mathrm{K}$. Level diagnosis of symptomatic urinary tract infections in childhood. Acta Paediatr Scand 1975; 64: 201-8.

24 Winberg J. Clinical aspects of urinary tract infection. In Holliday MA, Barratt TM, Vernier RL eds. Pediatric nephrology. Baltimore: Williams and Wilkins, 1987 626-46.

25 Jakobsson B, Söderlundh S, Berg U. Diagnostic significance of $99 \mathrm{~m}$ Tc-dimercaptosuccinic acid (DMSA) scintigraphy in urinary tract infection. Arch Dis Child 1992; 67: 1338-42.

26 Berg UB. Renal dysfunction in recurrent urinary tract infections in childhood. Pediatr Nephrol 1989; 3: 9-15.

27 Berg U. Long-term follow up of renal morphology and function in children with recurrent pyelonephritis. $\mathcal{F}$ Urol function in children

28 Majd $M$, Rushton HG, Jantausch B, Wiederman BL Relationship among vesicoureteral reflux, P-fimbriated Escherichia coli, and acute pyelonephritis in children with febrile urinary tract infection. $\mathcal{f}$ Pediatr 1991; 119: 578-85.

29 Svanborg Edén C, Hansson S, Jodal U, et al. Host-parasite interaction in the urinary tract. $\mathcal{F}$ Infect Dis $1988 ; 157$ 421-6. 